\title{
Influence of Spray Parameters on the Thickness, Hardness and Porosity of low-pressure Cold Sprayed WC-Ni Coatings
}

Wania Jibran ( $\nabla$ wjibran@ualberta.ca )

University of Alberta https://orcid.org/0000-0002-2082-4467

James Hogan

University of Alberta

André McDonald

University of Alberta

\section{Research Article}

Keywords: ANOVA, Design of Experiments, Factorial Design, Low-pressure cold spray (LPCS), Parameter Optimization

Posted Date: February 24th, 2021

DOI: https://doi.org/10.21203/rs.3.rs-225879/v1

License: (9) This work is licensed under a Creative Commons Attribution 4.0 International License. Read Full License

Version of Record: A version of this preprint was published at The International Journal of Advanced Manufacturing Technology on July 6th, 2021. See the published version at https://doi.org/10.1007/s00170-021-07500-w. 


\section{Abstract}

In this study, a $3^{3}$ full factorial design methodology was used to analyze the effects of spray parameters on the thickness, hardness, and surface porosity of low-pressure cold-sprayed WC-17Ni coatings. Three levels were selected for the spray parameters included in the design which were the powder feed rate $(17.1 \mathrm{~g} / \mathrm{min}, 21.1 \mathrm{~g} / \mathrm{min}$, and $23.7 \mathrm{~g} / \mathrm{min})$, gas temperature $\left(475^{\circ} \mathrm{C}, 500^{\circ} \mathrm{C}\right.$, and $\left.525^{\circ} \mathrm{C}\right)$, and the nozzle to substrate stand-off distance ( $3 \mathrm{~mm}, 5 \mathrm{~mm}$, and $10 \mathrm{~mm}$ ). It was found that the feed rate was the most significant parameter that affected the coating thickness. The surface porosity was most significantly affected by stand-off distance. The coating hardness was most influenced by the interaction between the feed rate and stand-off distance. An optimization study was then performed to maximize the coating thickness and hardness while minimizing the surface porosity. The optimal spray parameters (OSP) were found to be at a feed rate of $23.7 \mathrm{~g} / \mathrm{min}, 500^{\circ} \mathrm{C}$ for the carrier gas temperature, and $10 \mathrm{~mm}$ for the standoff distance. The OSP yielded a coating that was $1.22 \pm 0.06 \mathrm{~mm}$ thick, with a hardness of $364.5 \pm 8.5$ $\mathrm{HV}$ and porosity of $6.8 \pm 0.6 \%$. With a multi-parameter process, the system response is affected by both the variation in the individual parameters and the interaction of the parameters with each other. It was also concluded that the interaction between the parameters significantly affected the coating hardness. These results suggest that variation of the selected parameters produce statistically significant effects on the coating quality of WC-17Ni coatings using a low-pressure cold spray system.

\section{Introduction}

\subsection{Thermally Sprayed WC-based MMC Coatings}

Metal matrix composite (MMC) coatings reinforced with tungsten carbide (WC) are widely used in industry due to their enhanced wear resistance and hardness [1-3]. Thermally sprayed WC-based MMC coatings are often preferred for repair jobs as it is more feasible to coat prepared parts rather than preparing and machining bulk WC. Due to their improved wear and hardness properties, WC-Ni coatings are useful for surface protection and repair in aggressive wear environments. WC-Ni coatings are currently being used for surface protection and repair in pipelines, aircraft engines, and steam and jet engines to mitigate erosion due to particle impingement [2,3]. The most typical method of depositing WCbased MMC coatings is with high temperature high-velocity oxy-fuel (HVOF) spraying. HVOF-sprayed WC coatings are used for various surface modification applications [4-11]. However, using high temperature deposition methods often lead to undesirable metallurgical changes [9], phase transformations [9], and residual stresses [11] in the coatings. The most common problem in WC-based MMC coatings fabricated using high temperature deposition methods is decarburization $[9,11]$. Studies have shown that decarburization in WC-based MMC coatings introduces brittle phases, which negatively affect the abrasion resistance of the coatings [8-10].

In order to mitigate problems such as decarburization and phase changes induced by high temperature deposition methods, other forms of thermal spraying have been considered. A method known as warm spraying, where nitrogen is mixed with the flame during HVOF to lower the temperature of the flame, has 
been used to create WC-based MMC coatings which have shown to have reduced decarburization and comparable mechanical properties as HVOF-sprayed coatings [12-13]. In order to eliminate decarburization completely, a thermal spraying method called cold gas dynamic spraying or cold spraying has been employed. Cold spraying is a solid-state deposition process that is used to fabricate dense and thick MMC coatings. The deposition is carried out by accelerating powdered metal or ceramic particles ( 1 to $45 \mu \mathrm{m}$ in size) at high velocities (500-1500 m/s) using a carrier gas. As the name implies, cold spraying is performed at low temperatures, which ensures that decarburization does not occur. The carrier gas is maintained at temperatures lower than the melting point of the feedstock material, which also eliminates undesirable metallurgical changes induced during melting [14]. The particles attain high kinetic energy as they go through a de Laval nozzle which leads to severe plastic deformation of the powder particles upon impact on the substrate. The deposition occurs as particles flatten due to particlesubstrate or particle-particle impacts, thereby creating successive layers of mechanically interlocking particles, which creates the coating [14-17]. The effect of spray parameters (e.g. feed rate, gas temperature and stand-off distance) involved in cold spraying on the coating is explored in this study.

Several researchers have used high-pressure ( 2 to $4 \mathrm{MPa}$ ) cold spraying to fabricate WC-based MMC coatings [18-19]. The coatings produced yielded hardness values of 900-2000 HV, which are comparable to the hardness values achieved using HVOF-spraying [20-21]. The coatings produced using high-pressure cold spray showed no evidence of decarburization [22]. The challenge faced using highpressure cold spraying was achieving sufficiently thick coatings. In one study, Gao, et al. [19] found that it was difficult to induce plastic deformation of WC-Co particles on previously deposited particles, which led to fabrication of thin coatings. Some researchers were able to create thick WC-based MMC coatings by pre-heating the feedstock powder [20]. This study explores the effect of spray parameters on the coating thickness achieved during a cold spray process.

Even though several studies have been performed on high-pressure cold sprayed WC-based MMC coatings, the studies performed are very limited for low-pressure cold sprayed WC-based MMC coatings. Some researchers have used low-pressure cold spraying to fabricate thick WC-based MMC coatings from ceramic powders admixed with a soft metal binder phase [23]. For example, Wang and Villafuerte deposited WC-Cu coatings using low-pressure cold spray, which yielded a hardness of 200 HB [24]. In another paper, Melendez and McDonald fabricated WC-Ni coatings using low-pressure cold spraying to produce coatings with hardness as high as $530 \mathrm{HV}_{0.3}$ [23]. No evidence of decarburization was found in the coatings created using low-pressure cold spraying. Although several studies have been conducted to produce thick, hard and dense WC-based coatings [8], [23], [25]-[27], very limited work exists that explores the optimization of these properties; which is the main focus of this study.

\subsection{Optimization Methods for MMC Coatings}

For any manufacturing processes, it is critical in modern, competitive industry that the manufacturing process is optimized. Most manufacturing processes involve process parameters that have an effect on one or more response characteristic. Therefore, simultaneous optimization of response characteristics is of immense importance to make the process as efficient as possible. Like other manufacturing 
processes, cold spraying is also a multi-parameter and multi-response process. Therefore, the process or operation parameters involved in a cold spray process, including, but not limited to, gas pressure, temperature, stand off distance, feed rate, powder morphology, substrate roughness, and substrate temperature can all have an effect on various characteristics of the coating [25-33]. Since cold spray coatings are often used for geometric and functional repairs, achieving desired characteristics, including coating thickness, hardness, density, and porosity is important. Therefore, optimization of process parameters is an essential part of any spray process.

Some researchers have explored optimization methods for various thermal spraying processes [34-37] such as plasma spraying and HVOF spraying. Since optimization is a crucial part of any production process, optimization methods are widely studied and they typically employ experimental methods [32], numerical analyses [25-27, 33, 35-38], or use artificial intelligence approaches [39]. In one study, Sarikaya [37] conducted an experimental optimization study for HVOF sprayed alumina coatings to analyze the effect of stand-off distance, substrate temperature, and surface roughness on the coating hardness, thickness, and porosity. Since this study was experimental, the effects of only a single process parameter were analyzed at a time, thereby disregarding the possible coupled relationship of those parameters. They concluded that increasing the substrate temperature enhanced the coating hardness, porosity and surface roughness. In another study, a real-time optimization method was employed by Liu, et al. [39] using artificial neural networks to achieve a desired coating porosity by changing the gas flow rates and current intensity in a plasma spraying process. Using experimental data, an artificial neural network framework was used to predict the coating porosity based on a given set of input parameters through machine learning. This enabled real-time, in situ optimization during a plasma spray process [39]. In a separate approach, Hong, et al. [38, 40] employed the Taguchi statistical method to understand and optimize the response of WC-Co coatings and iron-alloy coatings deposited using HVOF spraying. The effect of stand-off distance and oxygen and kerosene flow rates on the hardness of WC-Co coatings and the porosity of iron alloy coatings was analyzed [38]. They found that the kerosene flowrate had the greatest effect on the hardness of WC-Co coatings and porosity of the iron alloy coatings. It has also been found that stand-off distance, nozzle temperature and feed rate have greater impact on the coating density, thickness and surface roughness compared to other spray parameters for example traverse speed and substrate temperature [31-33]. This study explores the effects of feed rate, gas temperature and stand-off distance on the coating thickness, hardness and surface porosity.

Although several studies have been performed on optimizing HVOF and plasma spraying processes, there are fewer studies investigating parameter optimization for cold spray processes. Some of the existing work includes an experimental investigation conducted by Magaro, et al. [32] to investigate the effect of gas temperature, gas pressure, and nozzle traverse speed on the coating hardness and elastic modulus for Stellite 6 coatings deposited using a high-pressure cold spray process. It was found that reducing the traverse speed improves the coating hardness and elastic modulus [32]. Since cold spray processes involve several process parameters that may affect various coating characteristics (e.g. thickness, hardness, porosity), investigating these effects simultaneously becomes challenging using experimental methods alone as the required number of depositions increases exponentially with increasing 
parameters. Therefore, experimental studies alone tend to be very limited in the number of parameters and response characteristics investigated.

In their investigations, Goyal, et al. [34-36] conducted several studies to optimize the surface roughness, coating thickness, and density for low-pressure cold sprayed copper coatings using the Taguchi method. The process parameters analyzed in these studies were substrate material, gas pressure and temperature, and stand-off distance. It was concluded that the surface roughness was most affected by gas pressure, the coating thickness by stand-off distance, and coating density by substrate material [34-36]. The Taguchi method is designed to only investigate the effect of process parameters on one response characteristic. Therefore, the Taguchi method is limited to single response assemblies and is incapable of handling multi-response systems. To simultaneously analyze multiple responses, researchers often use factorial designs. For example, Villa, et al. [30] employed a $3^{2}$ fractional factorial design to optimize the density, porosity, and hardness of cold-sprayed steel coatings based on process gas temperature and pressure. It was concluded that coatings deposited at higher temperature and pressures yielded enhanced hardness, density and porosity [30]. Similarly, Hasniyati, et al. [28] conducted a $2^{4-1}$ fractional factorial study to optimize the coating hardness, thickness, and elastic modulus of cold sprayed hydroxyapatite coatings as functions of stand-off distance, substrate temperature, and surface roughness.

Although statistical methods like Taguchi and fractional factorial designs have been explored by several researchers to optimize cold spray processes, there is limited work for statistical optimization of WCbased MMC coatings deposited using cold spray processes for larger experimental spaces. Therefore, there is limited research about simultaneous optimization of 3 or more process parameters and their effect on several different response characteristics. As the experimental space increases with the increase of process parameters and response characteristics that are analyzed, the number of experiments required to achieve statistically significant results increases exponentially [41]. Building on these past works and concepts, the objectives of this study are to analyze the effects of spray parameters on the hardness, thickness, and surface porosity of low-pressure cold sprayed WC-Ni coatings using a $3^{3}$ full factorial design and Analysis of Variance (ANOVA) approach. Once relationships are established, including coupled effects, the model is used to optimize the coating design.

\section{Experimental Procedure}

\subsection{Materials and Cold Spray Procedure}

Low carbon steel was used as the substrate in this study. The substrates were $0.5 \mathrm{~mm}$ thick and were cut to a size of $4 \mathrm{~cm}$ by $2 \mathrm{~cm}$. The substrates were grit blasted using \#24 alumina grit to roughen the surface and improve coating adhesion (Manus Abrasive Systems Inc., Edmonton, AB, Canada). The coating material was a mechanically mixed blend of Ni (N5001, Centerline Ltd., Windsor, ON, Canada), which was the metal matrix, and WC (Oerlikon Metco, Westbury NY, USA), which was the hard, reinforcing phase. The powders were weighed and mixed manually to achieve the desired composition for the powder blend of $83 \mathrm{wt} . \% \mathrm{WC}$ and $17 \mathrm{wt} . \% \mathrm{Ni}$. The size distribution of the as-received Ni and WC powders was 5 to $45 \mu \mathrm{m}$, 
as provided by the manufacturer. The powder morphology for both feedstock powders is shown in Fig. 1 . As observed in Fig. 1, Ni particles appear to be dendritic in structure and the WC particles appear to be angular with sharper edges.

The coating deposition was carried out using a low-pressure cold spray nozzle (SST SeriesP, Centerline Ltd., Windsor, ON, Canada) that was manipulated by a fixed robot assembly (HP-20, Motoman, Yaskawa Electric Corp., Waukegan, IL, USA). To analyze the effect of the spray parameters on the coatings, three controllable parameters were selected: stand-off distance, feed rate, and temperature. These three parameters were selected due to the significant effect that they have on the deposited coating and ease of controlling and varying the input. Temperature and feed rate were both controlled digitally using the interface on the cold spray system while the stand-off distance was changed consistently using the robot control system. All other spray parameters such as air pressure (634 kPa), nozzle traverse speed $(5 \mathrm{~mm} / \mathrm{s})$ and the number of passes (2) were kept constant during the experiments. The experimental parameters used in the study are presented in Table 1 . The feed rate is denoted as A, gas temperature as B and stand-off distance as C.

Table 1

Spray parameters and the levels used for the $3^{3}$ full factorial design.

\begin{tabular}{|l|llll|}
\cline { 2 - 5 } & Parameter & Level 1 & Level 2 & Level 3 \\
\hline A: Feed Rate $[\mathrm{g} / \mathrm{min}]$ & 17.1 & 21.1 & 23.7 \\
\hline B: Temperature $\left[{ }^{\circ} \mathrm{C}\right]$ & 475 & 500 & 525 \\
\hline C: Stand-off Distance $[\mathrm{mm}]$ & 3 & 5 & 10 \\
\hline \multirow{4}{*}{2.2 Factorial Design Approach }
\end{tabular}

$\mathrm{A} 3^{3}$ full factorial design was used to determine which spray parameters most significantly affected the coating thickness, hardness, and surface porosity. The process was also designed to eliminate any parameters that had insignificant impact for future optimization studies. This design of experiments study was conducted using a statistical software (Minitab 19, Minitab Inc, Pennsylvania, USA). Three levels were selected for each spray parameter and were denoted as 1 (low), 2 (medium), and 3 (high) as shown in Table 1. The levels for the parameters were selected based on preliminary experiments. For a $3^{3}$ full factorial design, 27 unique design generators or parameter combinations were produced by the Minitab software. Analysis of variance (ANOVA) was used to determine the percent contribution of each of the parameters on the system response. Additionally, since a full factorial design was conducted, the contribution of the interaction between the spray parameters was also determined through ANOVA. Optimization analysis was performed to determine the optimal spray parameters (OSP) which would maximize the coating thickness and hardness and minimize surface porosity.

\subsection{Coating Microstructural Characterization}


The microstructure of the coatings was observed using a scanning electron microscope (Zeiss Sigma, Jena, Germany). The cross-sectional SEM images were taken at various locations in the coating using magnifications of 150 to $2000 \mathrm{X}$ and at a working piece distance of $8.4 \mathrm{~mm}$.

\subsection{Thickness, Hardness and Surface Porosity Measurements}

The coating thickness was measured using the SEM images and digital calipers with a resolution of $0.01 \mathrm{~mm}$. The coating thickness was taken as the measurement from the top surface of the coating to the surface of the substrate. A minimum of 5 thickness measurements were taken at various points for each coating sample to ensure repeatability in the results.

Coating hardness was measured using a microhardness testing machine (Buehler VH1202, Lake Bluff, Illinois, USA) in accordance with the ASTM E384-11 standard. All the coating samples were ground using 240, 360, 400 grit silicone carbide paper (LECO, Mississauga, ON, Canada) to achieve a uniform, flat surface. A load of $1 \mathrm{kgf}$ with dwell time of 10 seconds was used for the hardness testing with a minimum of 5 measurements for each coating sample.

The surface porosity of the coatings was measured using image analysis and thermal imaging. An image processing software (Image J, Maryland, USA) was used to analyze the cross-section and surface images of the coating to measure the porosity in the coating and at its surface. The as-sprayed coating samples were heated to $125^{\circ} \mathrm{C}$ for 5 minutes to generate a temperature distribution in the samples. The heated samples were then imaged using a thermal camera (FLIR x8503sc, FLIR Systems, Wilsonville, OR, USA). The porosity appeared as spherical defects on the coating surface as they appeared as areas of elevated temperatures as shown in Fig. 2. The images were cropped to a constant area of 100 by 100 pixels and were converted to grayscale using the ImageJ software. Thresholding was applied to segment the grayscale images and quantify the surface porosity of the coating samples as illustrated in Fig. 2 . The minimum size to quantify porosity was selected as 4 pixels.

\section{Results And Discussion}

\subsection{Coating Microstructure}

Figure 3 shows the polished cross-sectional microstructure of the cold-sprayed WC-Ni coating deposited using the optimal spraying parameters. As observed in the image, the interface between the coating and substrate does not contain any porosity and is well-adhered to the substrate material. Good adhesion and dense coatings can be attributed to the nature of the cold spray procedure as it is well documented for producing very dense coatings [26], [41]. There appears to be good retention of WC in the coating; however, the WC phase seems to be distributed non-homogeneously, which can lead to varying hardness at different locations in the coating. Similar morphology has been found by other researchers for coldsprayed WC-Ni coatings [26, 42]. 
The porosity of the coating deposited using the OSP was quantified using image processing by analyzing a minimum of 4 different SEM images taken from the coating cross section. It was found that the average cross-sectional porosity of the coating was $0.98 \pm 0.14 \%$, which is significantly smaller than the surface porosity of $6.8 \pm 0.6 \%$ for the OSP coating sample. The porosity measurement for the OSP coating is lower compared to the other coatings as illustrated in Figure 4. During the spray process, as the feed rate of the powder increases, the hard particles often rebound from the coating surface leaving surface defects that contribute to the higher surface porosity. A similar trend was found by Melendez and McDonald, where increased hard particle content lead to decreased deposition rates due to hard particle rebounding during impact [23]. The effect of particle rebound contributes less to the cross-sectional porosity. This is because the successive deposition of particles causes the pores in the coating crosssection to collapse, forming a more consolidated structure.

\subsection{Analysis of Parameter Effects}

To understand the effect of each spray parameter on the coating, response plots for each parameter and coating property were created as illustrated in Figure 4. The response plots illustrate the system response at each, separate level. It is observed in Figure 4 that the feed rate has the largest effect on the response between the three levels for coating thickness. According to Taguchi and factorial design principles, the larger the difference between the responses, the more influential the spray parameter is. Therefore, it can be concluded that the feed rate has the greatest influence on the coating thickness. It is evident from Figure 4, that increasing the feed rate increases the coating thickness. This can be attributed to the fact that increasing the feed rate in a spray process allows for more powder to be dispensed to the spray nozzle, which in turn leads to greater deposition onto the substrate, resulting in a thicker coating. It is also observed that increasing the gas temperature to $500^{\circ} \mathrm{C}$ causes the thickness response to increase. The deposition rate of particles increases with increase in temperature as increasing the temperature allows for enhanced thermal softening which is an essential bonding mechanism in cold spray coatings [30]. Increasing the stand-off distance from $3 \mathrm{~mm}$ to $5 \mathrm{~mm}$ also causes an increase in the thickness response. This can be explained by a phenomenon explored by Sarikaya where the in-flight particle temperature is described as a function of stand-off distance [37]. Increasing the stand-off distance increases the particle dwell time in the plume of the spray, which causes particle temperatures to rise [37]. Particles that attain higher temperatures will have improved bonding with the substrate thereby improving the deposition efficiency and coating thickness.

Similarly, for the coating hardness, it is seen in Figure 4, that the feed rate is the most influential spray parameter as it exhibits the largest difference in the response. It is observed that the hardness response increases significantly when the feed rate is increased to its maximum $[23.7 \mathrm{~g} / \mathrm{min}]$. As the feed rate increases, the content of WC in the coating also increases as more particles are dispensed in the spray plume. The increased content of WC promotes load sharing between the coating matrix and the hard particles, thereby yielding higher hardness values [26]. Greater content of WC in the coating increases the interfacial area available to share the load from the coating matrix during application of external loads [26]. Munday, et al. also concluded that increasing hard particle content leads to a decrease in the mean 
free path between hard particles which inhibits plastic deformation of the coating under loaded conditions by stopping coalescence of nucleated voids, thereby leading to harder coatings [26].

The response reaches a maximum when the stand-off distance goes from $3 \mathrm{~mm}$ to $5 \mathrm{~mm}$ (Figure 4); however, further increasing the stand-off to $10 \mathrm{~mm}$ decreases the response. The variation in the response as the stand-off distance is increased can be attributed to the powder particle impact velocity, which is influenced by the stand-off distance. Goyal, et al. found that having smaller stand-off distances increases the in-flight velocity of the impacting particles; therefore, for smaller stand-off distances, the impacting velocity of the particles is higher [34]. This higher net impact velocity creates a peening effect in the coating, consolidating it and causing it to become more dense. This consequently increases the coating hardness [34]. The phenomenon found by Sarikaya also explains the varying response of the coating hardness [37]. As established earlier, increasing the stand-off distance increases the particle dwell time in the spray plume causing the particle temperatures to increase. However, increasing the stand-off distance past an optimal point causes the particles to decrease in temperatures as the isotherms in the plume begin to decay [37]. Therefore, increasing the stand-off distance past a certain point causes the deposition rate to decrease and, consequently, causing the coating hardness to decrease. Coating hardness is also greatly affected by the amount of reinforcing particles like WC in the coating. Although the content of WC particles in the powder blend is held constant for this study, the amount of WC particles in the coating varies with changing operation parameters [26]. Therefore, it can also be concluded that the WC content in the coating is maximized when a stand-off distance of $5 \mathrm{~mm}$ is used, thus yielding higher hardness. Increasing the temperature to $500^{\circ} \mathrm{C}$ causes the coating hardness to increase. This response is in agreement with the coating thickness response to temperature increase.

Next, the surface porosity appears to be most influenced by the feed rate and the stand-off distance, as illustrated in Figure 4. As the stand-off distance increases from $3 \mathrm{~mm}$ to $10 \mathrm{~mm}$, the coating porosity decreases significantly. A similar trend was found by Qiao, et al. where increasing the stand-off distance led to increased particle dwell time in the plume leading to higher particle temperatures [40]. The increased particle temperatures enhance thermal softening leads to flatter particles upon impact that are easier to tile with the previously deposited particles, consequently collapsing the pores in the coating [40]. Increasing the feed rate causes the porosity response to increase (Figure 4), as hard particle rebounds increase with increasing feed rates leaving pores in the rebound locations. Though increasing the feed rate does yield a thicker coating, the coating contains more pores due to particle rebounds, thereby causing the porosity response to increase. The porosity response to temperature variation does not exhibit a clear trend (Figure 4) as the feed rate and stand-off distance exhibit antagonistic responses and their coupled response may overwhelm the response due to temperature variation alone. Additional fractional factorial studies can be conducted to get information about the coupled relationships of varying the feed rate, stand-off distance and temperature to make conclusions about the coupled responses.

\subsection{Analysis of Variance (ANOVA)}


The analysis of variance (ANOVA) was conducted using the statistical software Minitab to determine the significance of each spray parameter on the coating thickness, hardness and surface porosity, which is crucial to understanding and predicting the response of the system. ANOVA is performed by comparing the variability in the response contributed by each spray parameter with the total variability of the response. The total variability is the sum of squared deviations (SS) from the total mean of the response $(M S)$ for a total of $N$ samples. The $F$ ratios are calculated for each spray parameter and compared with the critical $F$ ratio which is found using the selected confidence interval $a$ and the degrees of freedom for the selected parameter $k$. For this study, if the $F$ ratio for a specific spray parameter is larger than 4.20 , that spray parameter can be concluded to have significant influence on the coating quality.

$$
\begin{gathered}
M S=\frac{S S}{N-k} \\
F_{\text {ratio }}=\frac{M S_{\text {parameter }}}{M S_{\text {error }}}
\end{gathered}
$$

Using equations 1 and 2, ANOVA was performed for the coatings generated. The ANOVA results for coating thickness, hardness and porosity are summarized in Table 2, Table3 and Table 4, respectively. It was found that the feed rate and stand-off distance both had significant influence on the coating thickness as their $F$ ratios were larger than 4.20. It was also found that the interaction between temperature and stand-off distance also had significant influence on the coating thickness, as seen in Table 2. The feed rate and stand-off distance were also the largest contributors in the coating response, contributing $31 \%$ and $28 \%$ of the total response respectively, as tabulated in Table 2 . All the other parameters and interactions were found to have insignificant influence on the coating thickness as they have $F$ ratios of less than 4.20 .

The ANOVA results for coating hardness and surface porosity concluded that none of the spray parameters had significant influence on the coating hardness and porosity as the $\mathrm{F}$ ratios were all below 4.20. It was found for the surface porosity, the greatest contribution to the response was $45 \%$ from the temperature. For the coating hardness, as indicated by the response plots (Fig. 4), the interaction between the parameters had a greater effect than the individual parameters themselves. As seen in Table 3, the largest contributor for the coating hardness is the interaction between feed rate and stand-off distance, contributing $37 \%$ of the overall response. The interaction between feed rate and temperature, and temperature and stand-off distance come in next contributing $27 \%$ and $23 \%$ of the effect, respectively. This further concludes that, unlike coating thickness and surface porosity, the coating hardness response is governed by the interaction effects between the spray parameters. Since the parameters all had $F$ values lower than 4.20 for the coating hardness and porosity (Table 4), their effects are concluded to be insignificant; however, it is advantageous to know the largest contributors that affect the coating hardness and surface porosity to allow for further investigations and optimization studies. The insignificance of these parameters for the coating hardness and surface porosity can be due to the large 
size of the experimental design or inherent inconsistencies in the system which overwhelm the statistical studies.

Table 2: ANOVA results for coating thickness.

\begin{tabular}{|llllll|}
\hline Symbol & Parameter & $\begin{array}{l}\text { Degrees of } \\
\text { Freedom }\end{array}$ & $\begin{array}{l}\text { Mean Sum of } \\
\text { Squares }\end{array}$ & $\begin{array}{l}\text { F } \\
\text { value }\end{array}$ & $\begin{array}{l}\text { Contribution } \\
{[\%]}\end{array}$ \\
\hline A & Feed Rate & 2 & 0.176 & 9.26 & 31.22 \\
\hline B & Temperature & 2 & 0.072 & 3.81 & 12.85 \\
\hline C & SOD & 2 & 0.160 & 8.41 & 28.35 \\
\hline$A^{*} \mathrm{~B}$ & $\begin{array}{l}\text { Feed Rate } \\
\text { Temperature }\end{array}$ & 4 & 0.016 & 0.83 & 2.80 \\
\hline$A^{*} \mathrm{C}$ & Feed Rate * SOD & 4 & 0.058 & 3.04 & 10.25 \\
\hline $\mathrm{B}^{*} \mathrm{C}$ & Temperature * SOD & 4 & 0.082 & 4.31 & 14.53 \\
\hline Error & & 8 & 0.019 & & \\
\hline Total & & 26 & & & \\
\hline
\end{tabular}

Table 3: ANOVA results for coating hardness.

\begin{tabular}{|llllll|}
\hline Symbol & Parameter & $\begin{array}{l}\text { Degrees of } \\
\text { Freedom }\end{array}$ & $\begin{array}{l}\text { Mean Sum of } \\
\text { Squares }\end{array}$ & $\begin{array}{l}\text { F } \\
\text { value }\end{array}$ & $\begin{array}{l}\text { Contribution } \\
{[\%]}\end{array}$ \\
\hline A & Feed Rate & 2 & 241.15 & 0.42 & 8.27 \\
\hline B & Temperature & 2 & 91.01 & 0.16 & 3.15 \\
\hline C & SOD & 2 & 26.13 & 0.05 & 0.98 \\
\hline$A * B$ & $\begin{array}{l}\text { Feed Rate } \\
\text { Temperature }\end{array}$ & 4 & 799.07 & 1.38 & 27.17 \\
\hline$A * C$ & Feed Rate* SOD & 4 & 1097.16 & 1.90 & 37.40 \\
\hline$B * C$ & Temperature * SOD & 4 & 676.25 & 1.17 & 23.03 \\
\hline Error & & 8 & 578.55 & & \\
\hline Total & & 26 & & & \\
\hline
\end{tabular}

Table 4: ANOVA results for surface porosity. 


\begin{tabular}{|llllll|}
\hline Symbol & Parameter & $\begin{array}{l}\text { Degrees of } \\
\text { Freedom }\end{array}$ & $\begin{array}{l}\text { Mean Sum of } \\
\text { Squares }\end{array}$ & $\begin{array}{l}\text { F } \\
\text { value }\end{array}$ & $\begin{array}{l}\text { Contribution } \\
{[\%]}\end{array}$ \\
\hline A & Feed Rate & 2 & 4.028 & 0.1 & 4.74 \\
\hline B & Temperature & 2 & 37.918 & 0.95 & 45.02 \\
\hline C & SOD & 2 & 19.037 & 0.48 & 22.75 \\
\hline$A^{*} \mathrm{~B}$ & $\begin{array}{l}\text { Feed Rate } \\
\text { Temperature }\end{array}$ & 4 & 10.643 & 0.27 & 12.80 \\
\hline$A^{*} \mathrm{C}$ & Feed Rate * SOD & 4 & 10.028 & 0.25 & 11.85 \\
\hline $\mathrm{B}^{*} \mathrm{C}$ & Temperature * SOD & 4 & 2.438 & 0.06 & 2.84 \\
\hline Error & & 8 & 39.891 & & \\
\hline Total & & 26 & & & \\
\hline
\end{tabular}

\subsection{Optimizing Operation Parameters}

Using the results from the effects plots and ANOVA, an optimization study was performed using Minitab to determine the optimal spray parameters (OSP) that would produce the best coating quality possible for this system. The goals for this optimization study were to maximize the coating thickness and hardness, while minimizing the surface porosity. The goals were selected in order to produce the thickest and hardest coating possible to achieve improved wear and erosion performance [42], and to achieve thicker coatings to increase the coating life span [43]. The porosity was selected to be minimized to achieve a more uniform, less porous coating to avoid localized areas of increased stress in loaded conditions [44]. The optimal spray parameters (OSP) were found to be $23.7 \mathrm{~g} / \mathrm{min}$ for the feed rate, $500^{\circ} \mathrm{C}$ for the temperature and $10 \mathrm{~mm}$ for the stand-off distance. The OSP would yield a coating that is $1.22 \pm 0.06 \mathrm{~mm}$ thick, with a hardness of $364.5 \pm 8.5 \mathrm{HV}$, and a porosity of $6.8 \pm 0.6 \%$.

\section{Conclusion}

The influence of spray parameters on the thickness, hardness and surface porosity of a low-pressure cold sprayed WC- 17wt.\% Ni coating were analyzed using a full factorial design study. The spray parameters analyzed were feed rate, temperature and stand-off distance. With the objective of optimizing the spray parameters to maximize the coating thickness and hardness while minimizing the surface porosity, the following conclusions were made:

1. The optimal spray parameters were found to be $23.7 \mathrm{~g} / \mathrm{min}$ for the feed rate, $500^{\circ} \mathrm{C}$ for the temperature and $10 \mathrm{~mm}$ for the stand-off distance. This set of spray parameters would yield a coating that is $1.22 \mathrm{~mm}$ thick, with a hardness and surface porosity of $364.5 \mathrm{HV}$ and $6.8 \%$, respectively, making it the best possible coating within the parameter ranges selected in the design. 
2. The most influential parameter for the coating thickness was the powder feed rate. The surface porosity was most influenced by the nozzle to substrate stand-off distance. The coating hardness was most influenced by the interaction between the feed rate and stand-off distance.

3. The interaction between the spray parameters also affected the quality of coating produced. The most important interaction for the coating thickness was between temperature and stand-off distance. For surface porosity, interactions between the feed rate and temperature, and feed rate and stand-off distance were important and influential. For the coating hardness, interactions between all three parameters were found to be largely influential.

4. The OSP created a coating that was dense and contained minimal porosity. The coating also portrayed excellent adhesion to the substrate as evident in the SEM images of the cross section.

\section{Declarations}

\section{Acknowledgements}

The authors gratefully acknowledge funding support from the Natural Science and Engineering Research Council Canada, the Canada Foundation for Innovation, and the Province of Alberta. Special thanks to Kapil Bhagavathula from the Center for Design of Advanced Materials at the University of Alberta for assistance with the thermal camera and training for hardness testing.

\section{Funding:}

The authors gratefully acknowledge funding support from the Natural Science and Engineering Research Council Canada, the Canada Foundation for Innovation, and the Province of Alberta.

\section{Conflicts of interest/Competing interests}

The authors have no conflicts of interest to declare that are relevant to the content of this article.

\section{Availability of data and material}

Data sets available as electronic files.

\section{Code availability}

Not Applicable

\section{Authors' contributions}

Wania Jibran: Conceptualization; Methodology; Data curation; Formal analysis; Investigation; Visualization; Roles/Writing - original draft

James Hogan: Conceptualization; Funding acquisition; Investigation; Methodology; Project administration; Resources; Supervision; Writing - review \& editing 
André McDonald: Conceptualization; Funding acquisition; Investigation; Methodology; Project administration; Resources; Supervision; Writing - review \& editing

\section{Ethics approval}

Not applicable as the presented work does not involve any human/animal participants.

\section{Consent to participate}

Not applicable as the presented work does not involve any human/animal participants.

\section{Consent for publication}

All authors consent to the publication of the submitted work as mentioned in the cover letter, complete with signatures.

\section{References}

1. Alidokht SA, Yue S, Chromik RR, Effect of WC morphology on dry sliding wear behavior of coldsprayed Ni-WC composite coatings, Surf. Coatings Technol., vol. 357, no. October 2018, pp. 849-863, 2019

2. Yin S, Ekoi EJ, Lupton TL, Dowling DP, Lupoi R, Cold spraying of WC-Co-Ni coatings using porous WC17Co powders: Formation mechanism, microstructure characterization and tribological performance, Mater. Des., vol. 126, no. January, pp. 305-313, 2017

3. Alidokht SA, Vo P, Yue S, Chromik RR, Erosive wear behavior of Cold-Sprayed Ni-WC composite coating, Wear, vol. 376-377, pp. 566-577, 2017

4. Zaha F, Kas M, Comparative Study of Thermally Sprayed Coatings Under Different Types of Wear Conditions for Hard Chromium Replacement, pp. 139-154, 2011

5. Liu Y, Qiao Y, He J, Lavernia EJ, Fischer TE, Samples A, Near-Nanostructured WC-18 Pct Co Coatings with Low Amounts of Non-WC Carbide Phase: Part II. Hardness and Resistance to Sliding and Abrasive Wear, vol. 33, no. January, pp. 159-164, 2002

6. Chivavibul P, Watanabe M, Kuroda S, Shinoda K, Effects of carbide size and Co content on the microstructure and mechanical properties of HVOF-sprayed WC - Co coatings, vol. 202, pp. 509521,2007

7. Henke H, Adam D, Köhler A, Heimann RB, Development and testing of HVOF-sprayed tungsten carbide coatings applied to moulds for concrete roof tiles, vol. 256, pp. 81-87, 2004

8. Kumari K, Anand K, Bellacci M, Giannozzi M, Effect of microstructure on abrasive wear behavior of thermally sprayed WC - 10Co - 4Cr coatings, Wear, vol. 268, no. 11-12, pp. 1309-1319, 2010

9. Stewart DA, Shipway PH, Mccartney DG, Abrasive wear behaviour of conventional and nanocomposite HVOF-sprayed WC - Co coatings, pp. 789-798, 1999 
10. Celik E, Culha O, Uyulgan B, Azem NFA, Ozdemir I, Turk A, Assessment of microstructural and mechanical properties of HVOF sprayed WC-based cermet coatings for a roller cylinder, vol. 200, pp. 4320-4328, 2006

11. Guilemany JM, De Paco JM, Nutting J, Miguel JR, Characterization of the W 2 C Phase Formed during the High Velocity Oxygen Fuel Spraying of a WC $\otimes 12$ Pct Co Powder, vol. 30, no. August, 1999

12. Chivavibul P, Watanabe M, Kuroda S, Kawakita J, Komatsu M, Effect of Powder Characteristics on Properties of Warm-Sprayed WC-Co Coatings, vol. 19, no. January, pp. 81-88, 2010

13. Chivavibul P, Watanabe M, Kuroda S, Kawakita J, Komatsu M, Development of WC-Co Coatings Deposited by Warm Spray Process, vol. 17, no. December, pp. 750-756, 2008

14. Assadi H, Gärtner F, Stoltenhoff T, Kreye H (2003) Bonding mechanism in cold gas spraying. Acta Mater 51(15):4379-4394

15. Hussain T, Mccartney DG, Shipway PH, Zhang D, Bonding Mechanisms in Cold Spraying: The Contributions of Metallurgical and Mechanical Components, vol. 18, no. September, pp. 364-379, 2009

16. Schmidt T, Ga F, Assadi H, Kreye H, Development of a generalized parameter window for cold spray deposition, vol. 54, pp. 729-742, 2006

17. Dewar MP, McDonald AG, Gerlich AP, Interfacial heating during low-pressure cold-gas dynamic spraying of aluminum coatings, pp. 184-198, 2012

18. Lima RS, Karthikeyan J, Kay CM, Lindemann J, Berndt CC, Microstructural characteristics of coldsprayed nanostructured WC - Co coatings, vol. 416, pp. 129-135, 2002

19. Gao P, Li C, Yang G, Li Y, Li C, Applied Surface Science Influence of substrate hardness transition on built-up of nanostructured WC - 12Co by cold spraying, vol. 256, pp. 2263-2268, 2010

20. Kim H, Lee C, Hwang S, Fabrication of WC - Co coatings by cold spray deposition, vol. 191, pp. 335340, 2005

21. Gao P, Li Y, Li C, Yang G, Li C, Influence of Powder Porous Structure on the Deposition Behavior of Cold-Sprayed WC-12Co Coatings, vol. 17, no. December, pp. 742-749, 2008

22. Dosta S, Couto M, Guilemany JM (2013) Cold spray deposition of a WC-25Co cermet onto Al7075-T6 and carbon steel substrates. Acta Mater 61(2):643-652

23. Melendez NM, McDonald AG (2013) Development of WC-based metal matrix composite coatings using low-pressure cold gas dynamic spraying. Surf Coatings Technol 214:101-109

24. Wang J, Villafuerte J (2009) Low pressure cold spraying of tungsten carbide composite coatings. Adv Mater Process 167(2):54-56

25. Alidokht SA, Vo P, Yue S, Chromik RR (2017) Cold Spray Deposition of Ni and WC-Reinforced Ni Matrix Composite Coatings. J Therm Spray Technol 26(8):1908-1921

26. Munday G, Hogan J, McDonald A (2020) On the microstructure-dependency of mechanical properties and failure of low-pressure cold-sprayed tungsten carbide-nickel metal matrix composite coatings. Surf Coatings Technol 396:no. May, p. 125947 
27. Sacks N (2016) Low pressure cold gas dynamic spraying of tungsten carbide-nickel coatings. Met Powder Rep 71(5):356-358

28. Hasniyati MR, Zuhailawati H, Sivakumar R, Dhindaw BK (2015) Optimization of multiple responses using overlaid contour plot and steepest methods analysis on hydroxyapatite coated magnesium via cold spray deposition. Surf Coatings Technol 280:250-255

29. Cavaliere P, Silvello A (2014) Processing parameters affecting cold spay coatings performances. Int J Adv Manuf Technol 71:no. 1-4 pp. 263-277

30. Villa M, Dosta S, Guilemany JM (2013) Optimization of 316 L stainless steel coatings on light alloys using Cold Gas Spray. Surf Coatings Technol 235:220-225

31. Goyal T, Walia RS, Sidhu TS (2013) Multi-response optimization of low-pressure cold-sprayed coatings through Taguchi method and utility concept. Int J Adv Manuf Technol 64:no. 5-8 pp. 903914

32. Magarò P, Marino AL, Di Schino A, Furgiuele F, Maletta C, Pileggi R, Sgambitterra E, Testani C, Tului M (2019) Surface \& Coatings Technology Effect of process parameters on the properties of Stellite-6 coatings deposited by Cold Gas Dynamic Spray. Surf Coat Technol 377:no. August, p. 124934

33. Klinkov SV, Kosarev VF, Rein M (2005) Cold spray deposition: Significance of particle impact phenomena. Aerosp Sci Technol 9(7):582-591

34. Goyal T, Walia RS, Sidhu TS (2012) Effect of parameters on coating density for cold spray process. Mater Manuf Process 27(2):193-200

35. Goyal T, Walia RS, Sidhu TS (2012) Study of coating thickness of cold spray process using Taguchi method. Mater Manuf Process 27(2):185-192

36. Goyal T, Walia RS, Sidhu TS (2012) Surface roughness optimization of cold-sprayed coatings using Taguchi method. Int J Adv Manuf Technol 60:no. 5-8 pp. 611-623

37. Sarikaya O, Effect of some parameters on microstructure and hardness of alumina coatings prepared by the air plasma spraying process, vol. 190, pp. 388-393, 2005

38. Hong S, Wu Y, Wang B, Zheng Y, Gao W, Li G (2014) High-velocity oxygen-fuel spray parameter optimization of nanostructured WC-10Co-4Cr coatings and sliding wear behavior of the optimized coating. Mater Des 55:286-291

39. Liu T, Planche MP, Kanta AF, Deng S, Montavon G, Deng K, Ren Z (2013) Plasma spray process operating parameters optimization based on artificial intelligence. Plasma Chem Plasma Process 33(5):1025-1041

40. Qiao L, Wu Y, Hong S, Cheng J, Wei Z, Influence of the high-velocity oxygen-fuel spray parameters on the porosity and corrosion resistance of iron-based amorphous coatings, Surf. Coat. Technol., vol. 366, no. December 2018, pp. 296-302, 2019

41. Mukerjee R, Wu CFJ, A Modern Theory of Factorial Design. Springer Science \& Business Media, 2007

42. Lee YTR, Ashrafizadeh H, Fisher G, McDonald A (2017) Effect of type of reinforcing particles on the deposition efficiency and wear resistance of low-pressure cold-sprayed metal matrix composite 
coatings. Surf Coatings Technol 324:190-200

43. Zhang N, Yang F, Li L, Shen C, Castro J, Lee LJ (2013) Thickness effect on particle erosion resistance of thermoplastic polyurethane coating on steel substrate. Wear 303:no. 1-2 pp. 49-55

44. Lioma D, Sacks N, Botef I (2015) Cold gas dynamic spraying ofWC-Ni cemented carbide coatings. Int J Refract Met Hard Mater 49(1):365-373

\section{Figures}


(a)
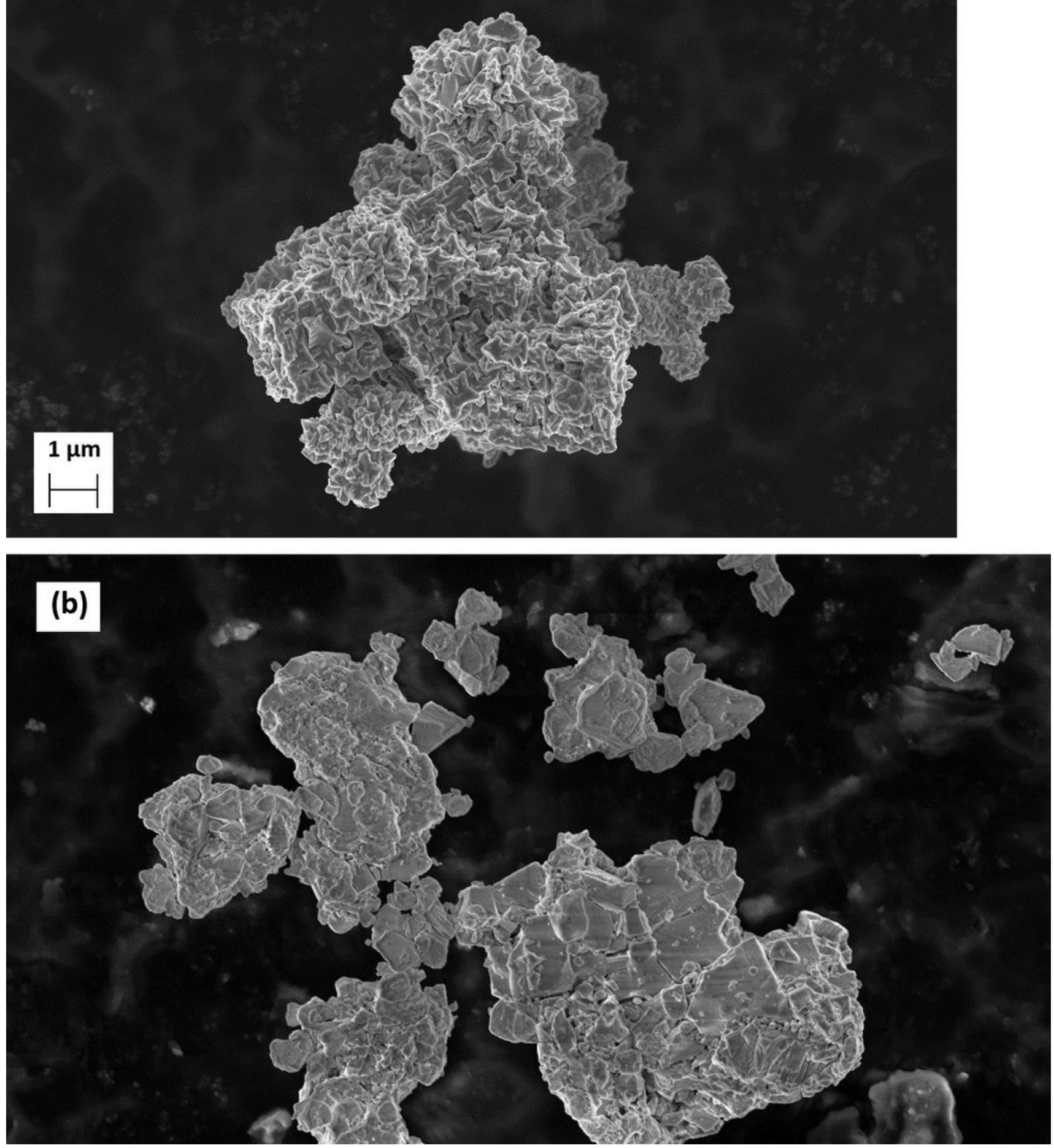

Figure 1

SEM images of the powder morphology for (a) Ni and (b) WC. 


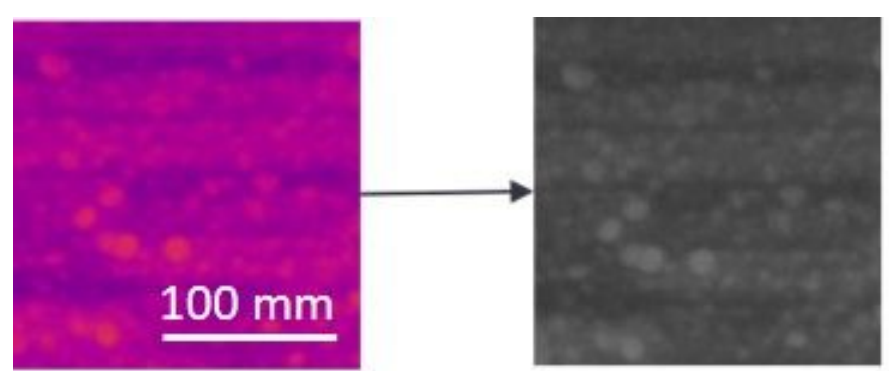
Original image

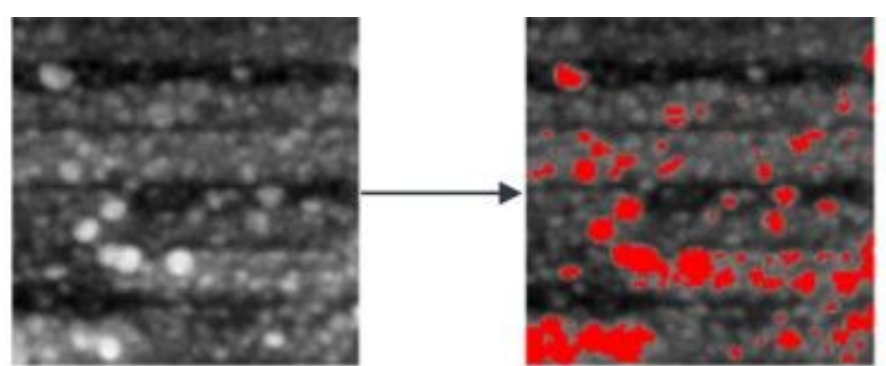

Segmented image
Calculate porosity

\section{Figure 2}

Process to convert thermal images to grayscale and apply thresholding to quantify surface porosity.

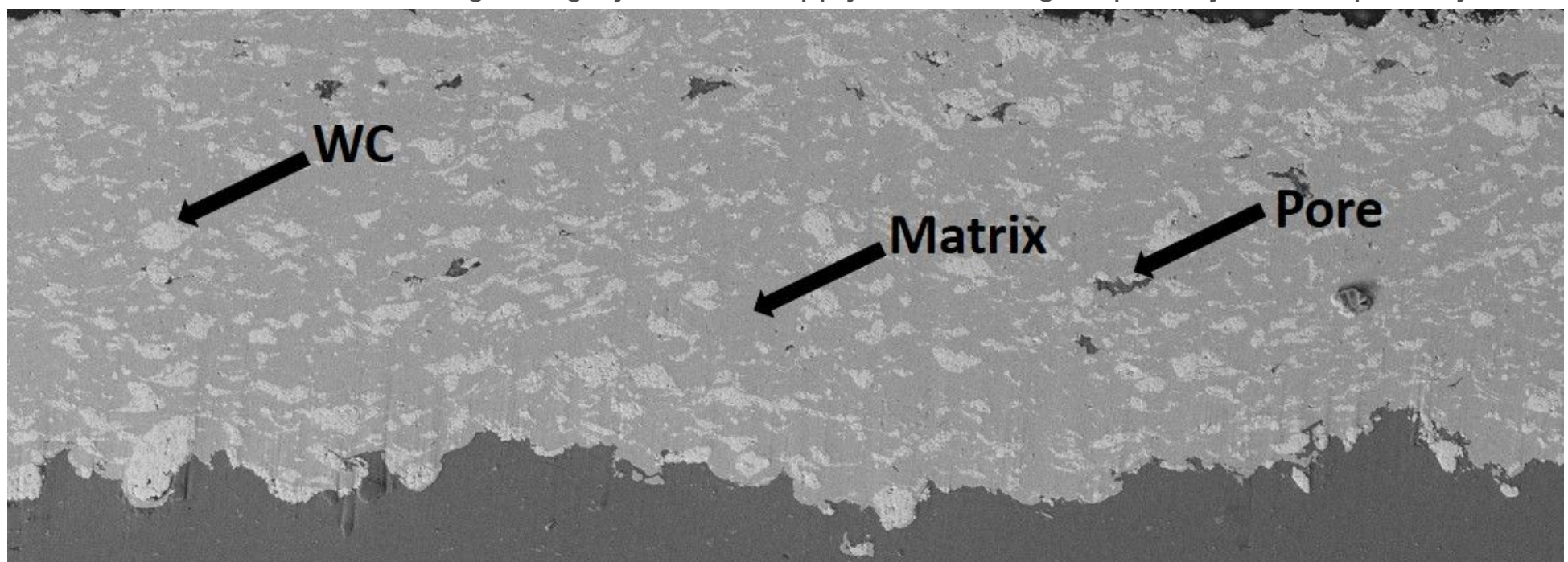

Figure 3

SEM image of the cross-section of the WC-17Ni coating deposited using OSP. 


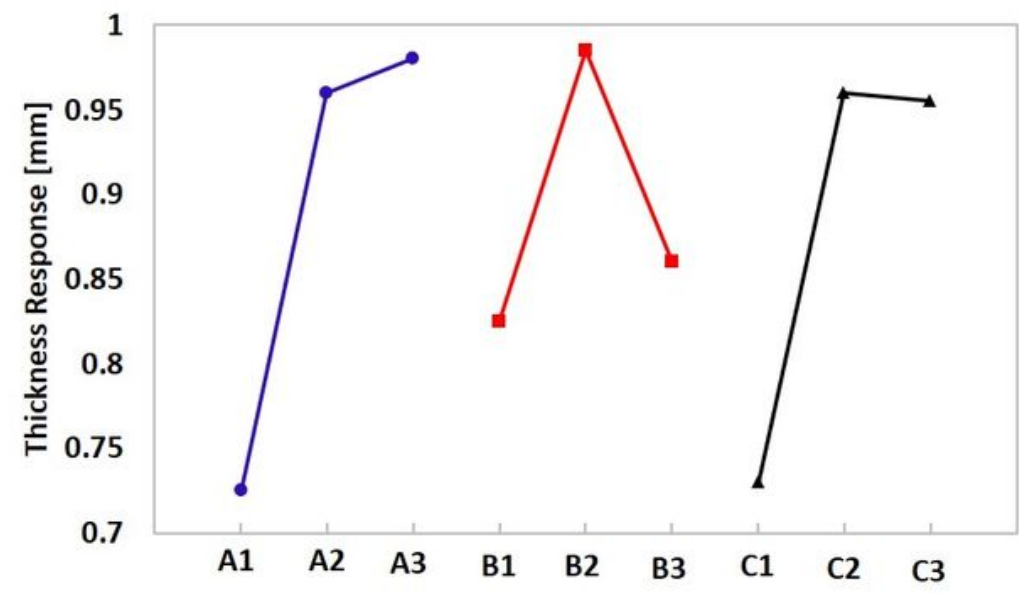

Spray Parameters
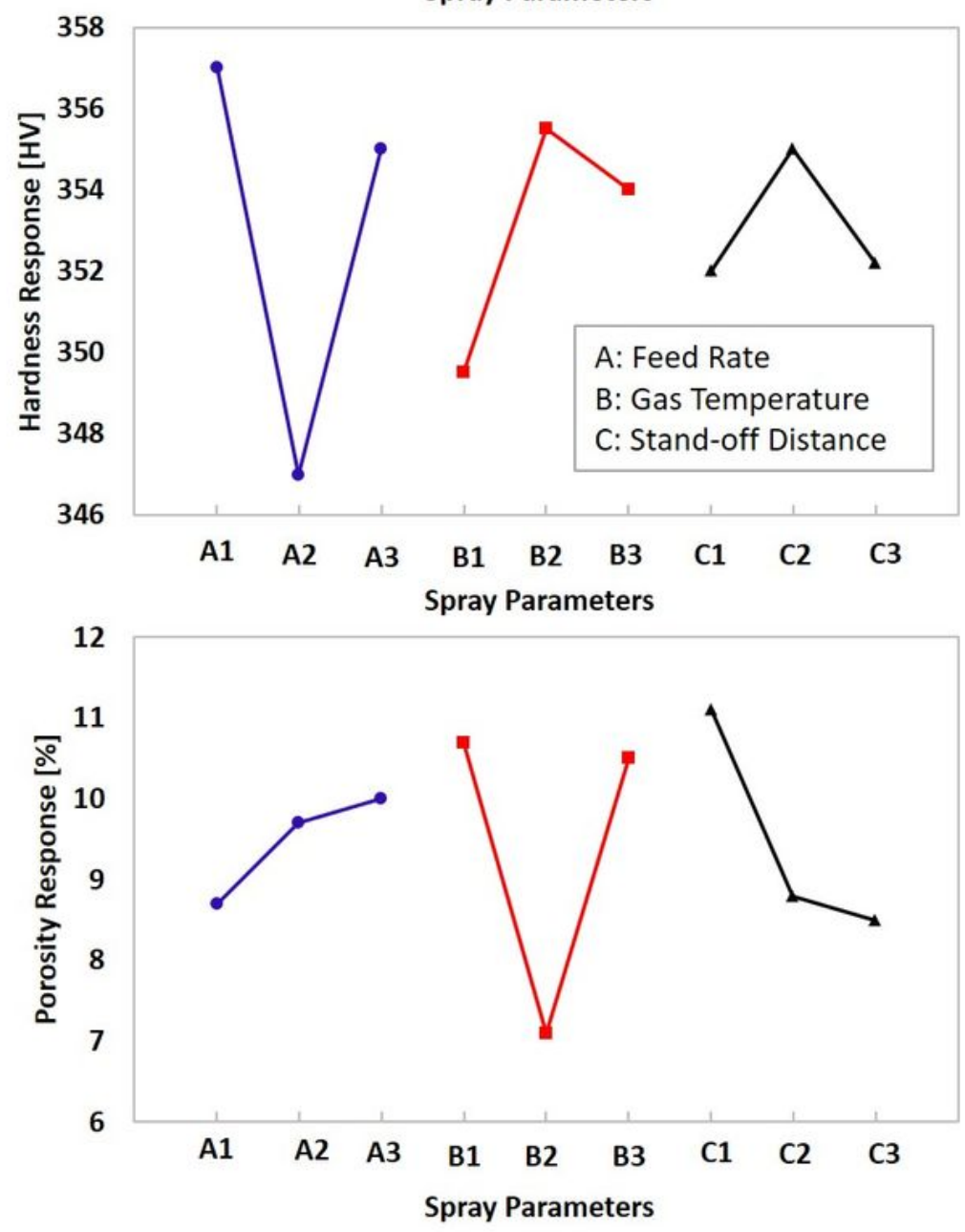

\section{Figure 4}

System response to parameter variation for coating thickness, hardness and surface porosity. 